(C) 1981. The Genetical Society of Great Britain

\title{
LATITUDINAL CLINE IN A COLOUR PATTERN POLYMORPHISM IN THE AUSTRALIAN GRASSHOPPER PHAULACRIDIUM VITTATUM
}

\author{
JOHN M. DEARN \\ Department of Genetics, University of Melbourne, Parkville, Victoria, Australia 3052
}

Received 24.xi.80

\section{SUMMARY}

\begin{abstract}
Phaulacridium vittatum is polymorphic for three colour pattern morphs involving the presence or absence of two white stripes on the head, pronotum and wings. The polymorphism is controlled by alleles at a single autosomal locus with the striped phenotype dominant. An examination of 47 populations in south-east Australia revealed a marked cline in morph frequency correlated with latitude. Possible reasons for the existence of the cline are discussed.
\end{abstract}

\section{INTRODUCTION}

GRASSHOPPERS are not noted for bright colouration, but their colouration can be very variable and disruptive patterns are common. While much of the variation appears to be quantitative and of ten subject to environmental influences such as density, temperature and humidity (Rowell, 1971), many species show discrete colour pattern morphs (Uvarov, 1966) and an association between colour pattern morphs and habitat characteristics has been demonstrated in two species (Peterson and Treherne, 1949; Gill, 1979). There have been only a few studies on the genetic basis of grasshopper colour pattern polymorphisms (Sansome and La Cour, 1935; Creighton and Robertson, 1941; King and Slifer, 1955; Byrne, 1967) and little is known about how selection might act on this variation.

Phaulacridium vittatum, commonly known as "the wingless grasshopper", is a small Australian acridid grasshopper widely distributed in pastures in Victoria, eastern N.S.W., Tasmania and south-west Western Australia (Key, 1938). This species exhibits a very striking colour pattern dimorphism involving the presence or absence of two white stripes on the dorsal surface of the head, pronotum and wings (Key, 1938). Many aspects of its biology suggest its suitability for ecological genetics studies. It can be reared in the laboratory and the polymorphism is present in all nymphal stages as well as the adult stage. It is univoltine with an egg diapause and hence has a simple population structure in the field. It is now one of the most numerous pasture pests in south-east Australia (Clark, 1962), and has a very wide distributional range extending from Tasmania in the south to southern Queensland in the north.

A preliminary analysis of three populations showed that the frequency of striped individuals varied significantly between populations (Dearn, 1978). This paper reports on an extensive geographic survey of the polymorphism together with the results of a study on the inheritance of the colour pattern morphs. 


\section{MATERIALS AND METHOdS}

\section{(i) The polymorphism}

It was previously thought that populations of $P$. vittatum were only dimorphic with respect to the presence or absence of two white stripes running along the head, pronotum and tegmen. It had been noted by Dearn (1978) that a few individuals were seen where the stripe pattern appeared only over the head and pronotum but because of their very low frequency they were classified as striped. The extensive geographic survey reported in this paper shows that this phenotype must be considered a distinct morph which although rare in the previously sampled southern part of the species distribution is common in the north. Thus, in this paper three pattern morphs are recognised, plain, striped and incomplete-striped (fig. 1). Formal descriptions of these morphs are not given here and the term incomplete-striped is intended to allow future modification or subdivision when more material is examined. The brown background colouration tends to be darker and the white stripes wider for the striped individuals compared with the incomplete-striped individuals. Within morphs there is quantitative variation for the darkness of the brown background colouration but no attempt has been made to quantify this.

Populations are also dimorphic for adult wing length and individuals are either macropterous and can fly or brachypterous and flightless. No association exists between the colour pattern polymorphism and the wing length dimorphism (Dearn, 1978) and the wing length dimorphism will not therefore be considered further in this paper.

\section{(ii) Rearing conditions}

$P$. vittatum has been successfully reared in the laboratory for a number of generations. Individuals were reared in 25 litre perspex cages in a room maintained at $22^{\circ} \mathrm{C}$ and the cages were further heated by an external $100 \mathrm{~W}$ bulb for 16 hours a day. Early instar stages were fed on clover leaves and bran flakes and late instar stages and adults were reared on cabbage leaves and bran flakes. Egg pods were collected in small paper cups containing damp sand then "seeded" into plastic containers containing damp sand. The egg pods were then incubated at $22^{\circ} \mathrm{C}$ for 2 weeks, then at $10^{\circ} \mathrm{C}$ for 10 weeks to break the egg diapause and then at $30^{\circ} \mathrm{C}$ until hatching.

\section{(iii) Inheritance studies}

Inheritance studies were limited to the striped and plain morphs since at the time of their inception the existence of the incomplete-striped morph was not known. The small clutch size and low laboratory survival of this species precludes single pair matings and instead mass matings were established involving only striped $\times$ striped and plain $\times$ plain matings. $P$. vittatum were collected as late instar morphs and hence virgins from a pasture at Gobur, $102 \mathrm{~km}$ north-east of Melbourne, Victoria, during 1978 and immediately separated into plain and striped classes and subsequently mass mated. The phenotypes of the progeny in the next generation (G1) were scored within 24 hours of hatching for both mating classes. At this stage 
Plate I

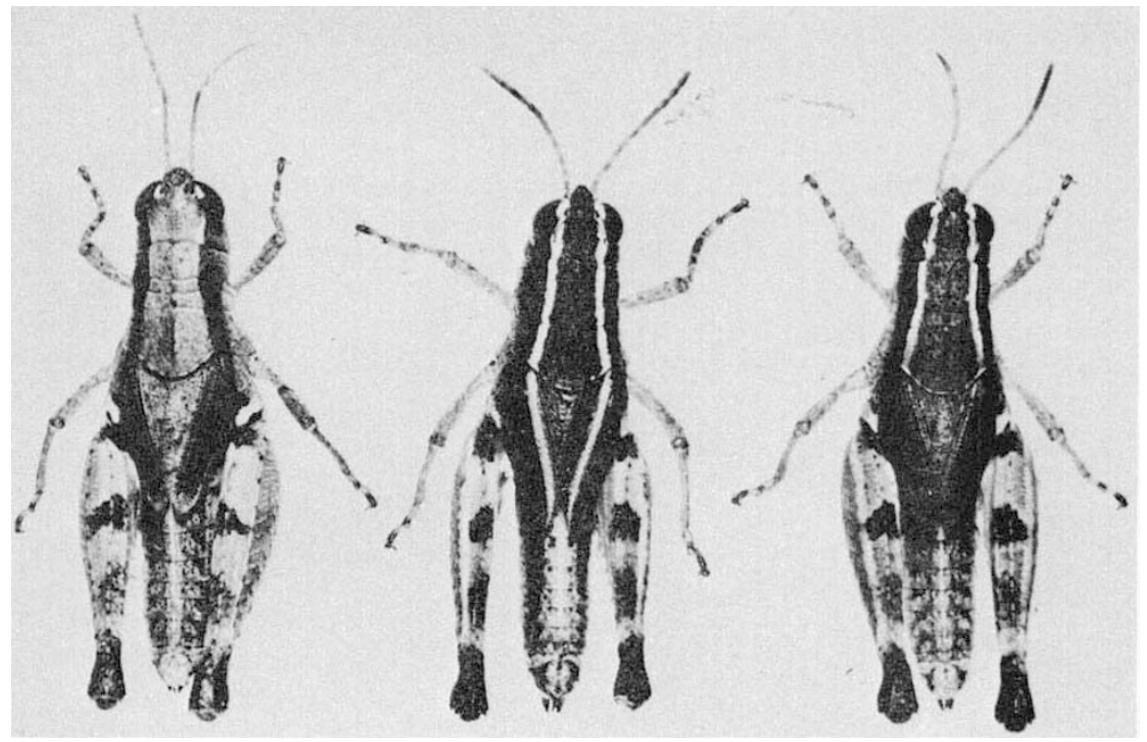

Fig. 1.-Brachypterous adult male $P$. vittatum. Left: plain morph, centre: striped morph, right: incomplete striped morph. 
striped and plain individuals were separated again and used to obtain a further generation (G2).

\section{(iv) Geographic variation}

Key (1938) records the distribution of $P$. vittatum in south-east Australia as coastal and sub-coastal on the wet side of the 20 -inch rainfall isohyet with a northern limit of $26^{\circ} \mathrm{S}$ (see his fig. 12). To encompass this range adult $P$. vittatum were collected from pasture sites on a north/south transect Toowoomba to Melbourne and the data from these collections have been supplemented in this paper with limited data from sites sampled in 1978 . The location of these sites is shown in fig. 2 and detailed location descriptions may be obtained from the author. All collections were made from grazed pasture sites using a sweep net. There are no significant differences in morph frequency between males and females and this paper presents only pooled data from both sexes. The average sample size for each site was 357 adults.

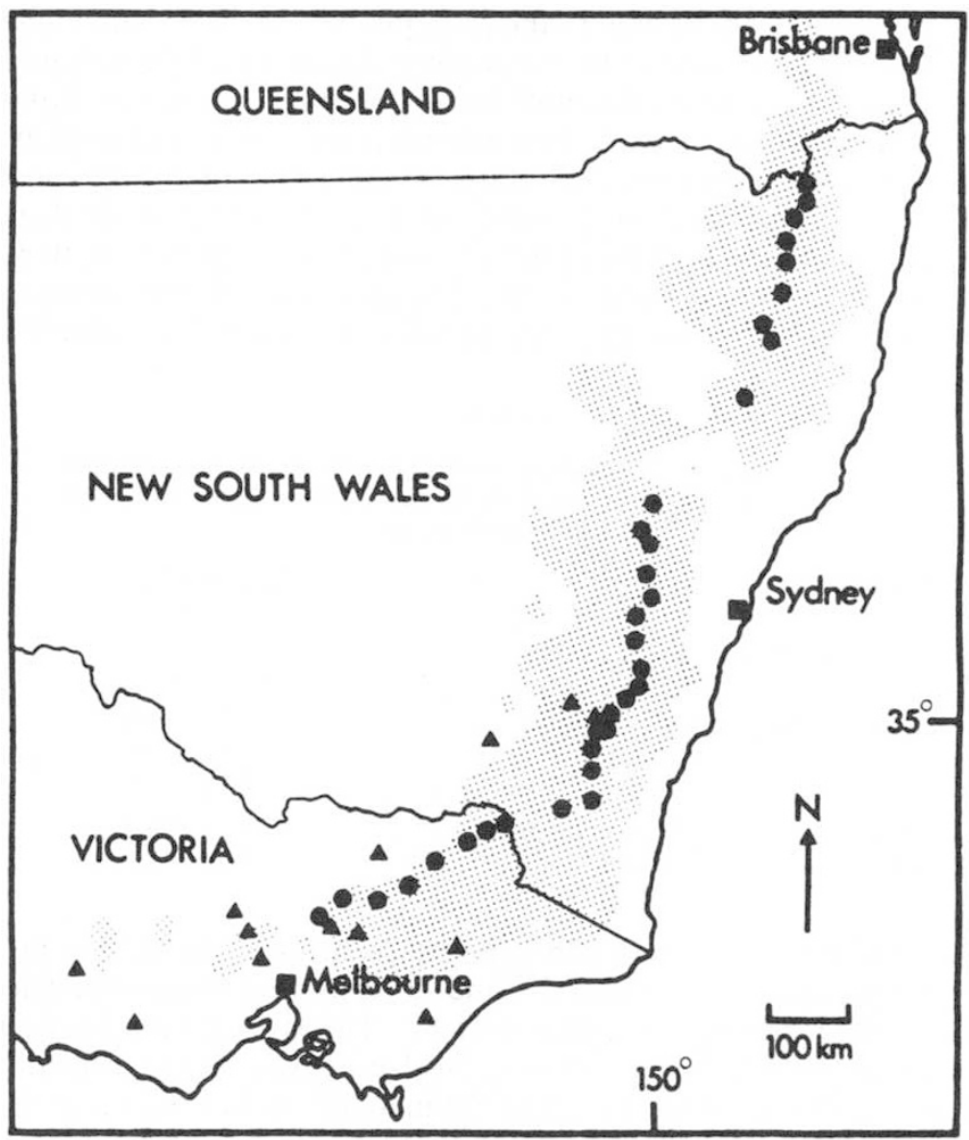

FIG. 2.-Map of south-east Australia showing the 1979/80 transect collection sites ( ) and the 1978 collection sites $(\Delta)$. The shaded area is land above $500 \mathrm{~m}$. 


\section{Results}

\section{(i) Inheritance studies}

(a) G1 of plain $\times$ plain and striped $\times$ striped matings

Of the 2487 progeny from plain $\times$ plain matings all were plain while the progeny of the striped $\times$ striped matings consisted of both striped and plain individuals (table 1). Taken together these data suggest that the

TABLE 1

Phenotype frequencies in the G1 and G2 progeny

\begin{tabular}{|c|c|c|c|c|c|}
\hline Generation & Mating & $\begin{array}{l}\text { Number of } \\
\text { striped } \\
\text { hatchlings }\end{array}$ & $\begin{array}{c}\text { Number of } \\
\text { plain } \\
\text { hatchlings }\end{array}$ & $\begin{array}{c}\text { Total } \\
\text { number of } \\
\text { hatchlings }\end{array}$ & $\begin{array}{c}\text { Frequency } \\
\text { of plain } \\
\text { hatchlings }\end{array}$ \\
\hline G1 & $\begin{array}{c}\text { Plain } \times \text { Plain } \\
\text { Striped } \times \text { Striped }\end{array}$ & $\begin{array}{r}0 \\
1721\end{array}$ & $\begin{array}{r}2487 \\
488\end{array}$ & $\begin{array}{l}2487 \\
2209\end{array}$ & $\begin{array}{l}1 \cdot 000 \\
0 \cdot 221\end{array}$ \\
\hline $\mathrm{G} 2$ & $\begin{array}{c}\text { Plain } \times \text { Plain } \\
\text { Striped } \times \text { Striped }\end{array}$ & $\begin{array}{r}0 \\
778\end{array}$ & $\begin{array}{r}1459 \\
88\end{array}$ & $\begin{array}{r}1459 \\
866\end{array}$ & $\begin{array}{l}1 \cdot 000 \\
0 \cdot 102\end{array}$ \\
\hline
\end{tabular}

striped phenotype is dominant to the plain phenotype. The simplest genetic model is that the colour pattern variation is determined by the segregation of two alleles at a single autosomal locus. In order to test this hypothesis the expected frequencies of the two morphs in the progeny of both matings can be estimated if one assumes Hardy-Weinberg equilibrium conditions in both field and laboratory populations even though a small degree of partial non-assortative mating has been observed in the field with respect to the pattern morphs (Dearn, 1979). The frequency of striped individuals in the Gobur population at the time of collection was $0 \cdot 25$. Table 2 shows

\section{TABLE 2}

Phenotype and genotype frequencies of the striped and plain morphs in the field population on the basis of the 2 allele single autosomal locus genetic model

$\begin{array}{lc}\text { Phenotypes } & \text { Striped }=0.25 \\ \text { Plain }=0.75 \\ \text { Gene frequencies } & C^{S}=0.134 \\ & C^{P}=0.866 \\ \text { Genotype frequencies } & C^{S} C^{S}=0.018 \\ & C^{S} C^{P}=0.232 \\ & C^{P} C^{P}=0.750 \\ \text { Proportion of SS and SP genotypes } & C^{S} C^{S}=0.072 \\ \text { amongst striped individuals } & { }^{S} C^{P}=0.928\end{array}$

the expected phenotype and genotype frequencies in the field population under this genetic model where $C^{P}$ and $C^{S}$ represent alternative alleles at a locus $C$ determining the colour pattern. The striped individuals which were used as parents for $\mathrm{G} 1$ should thus have given rise to individuals of all three genotypes with expected frequencies shown in table 3 . The expected frequency of plain individuals in G1 progeny from striped $\times$ striped matings under this model, $0 \cdot 215$, is close to the observed frequency of $0 \cdot 221$. 
TABLE 3

Genotype frequencies expected in the $G 1$ and $G 2$ progeny on the basis of
the genetic model
Genotypes of progeny and their frequency

(b) G2 of plain $\times$ plain and striped $\times$ striped matings

The plain and striped individuals from G1 were used to give a second generation of progeny. The frequencies of the two morphs in both matings in $\mathrm{G} 2$ are shown in table 1. Again, no striped individuals were observed in the plain $\times$ plain matings. The frequency of plain individuals expected in G2 progeny from striped $\times$ striped matings under the single locus model is $0 \cdot 101$ (table 3 ) which is very close to the observed frequency of $0 \cdot 102$.

\section{(c) Backcross matings}

In order to test further the genetic model suggested by the results of the mass matings, 15 backcross matings were set up using individual striped G1 males each mated to five plain females. Under the single locus model one would expect 0.37 of these males to be of the genotype $C^{s} C^{S}$ and thus give rise to only striped progeny while 0.63 of the males will be $C^{S} C^{P}$ and give rise to an expected ratio of $1: 1$ striped:plain progeny. Of the fifteen males tested nine were compatible with genotype $C^{s} C^{S}$ and six with genotype $C^{S} C^{P}$ (table 4 ) which is not significantly different from expected numbers $\left(\chi_{1}^{2}=3.40 P>0.05\right)$.

\section{(ii) Geographical variation}

Thirty four populations were sampled on a north/south transect during the summer of $1979 / 80$. The frequency of incomplete-striped individuals in relation to latitude is shown in fig. 3 and it can be seen that a low frequency of about 0.06 is observed over most of the latitudinal range except for the most southern populations near Melbourne where the frequency is extremely low, about $0 \cdot 001$. Prior to these $1979 / 80$ collections incomplete-striped individuals had been classified as striped because of their low frequency (Dearn, 1978). Limited data are available for the frequency of total striped individuals (striped plus incomplete-striped) for other populations in south-east Australia in 1978 and these have been included in fig. 4 together with data from the 1979/1980 transect. The frequency of total striped individuals shows a marked cline correlated with latitude from 0.06 in the north to 0.451 in the south. Unfortunately the genetic basis of the incomplete-striped phenotype is not yet known. 
TABLE 4

Number of striped and plain individuals in the progeny of 15 backcross matings each between a single striped G1 male and 5 plain $G 1$ females

\begin{tabular}{|c|c|c|c|}
\hline Mating & Striped & Plain & $\begin{array}{c}\text { Assumed } \\
\text { genotype of } \\
\text { male }\end{array}$ \\
\hline 1 & 18 & 0 & $C^{s} C^{s}$ \\
\hline 2 & 29 & 0 & $C^{s} C^{s}$ \\
\hline 3 & 81 & 0 & $C^{s} C^{s}$ \\
\hline 4 & 3 & 4 & $C^{s} C^{P}$ \\
\hline 5 & 45 & 0 & $C^{s} C^{s}$ \\
\hline 6 & 24 & 18 & $C^{s} C^{P}$ \\
\hline 7 & 22 & 0 & $C^{s} C^{s}$ \\
\hline 8 & 14 & 9 & $C^{s} C^{P}$ \\
\hline 9 & 48 & 0 & $C^{s} C^{s}$ \\
\hline 10 & 16 & 14 & $C^{s} C^{P}$ \\
\hline 11 & 23 & 0 & $C^{s} C^{s}$ \\
\hline 12 & 29 & 17 & $C^{s} C^{P}$ \\
\hline 13 & 41 & 0 & $C^{s} C^{s}$ \\
\hline 14 & 17 & 0 & $C^{s} C^{s}$ \\
\hline 15 & 12 & 11 & $C^{s} C^{P}$ \\
\hline
\end{tabular}

Nevertheless, the observed cline in the frequency of striped individuals suggests a corresponding cline in the frequency of the allele determining the striped phenotype of from close to zero in the north to approximately $0 \cdot 26$ in the south.

\section{Discussion}

The data obtained from the G1 and G2 matings and the backcrosses are all compatible with the colour pattern polymorphism in $P$. vittatum being determined by a single autosomal locus with two alleles and the striped phenotype dominant to the plain phenotype. This is in marked contrast with that found in other Orthopteran species where the few studies

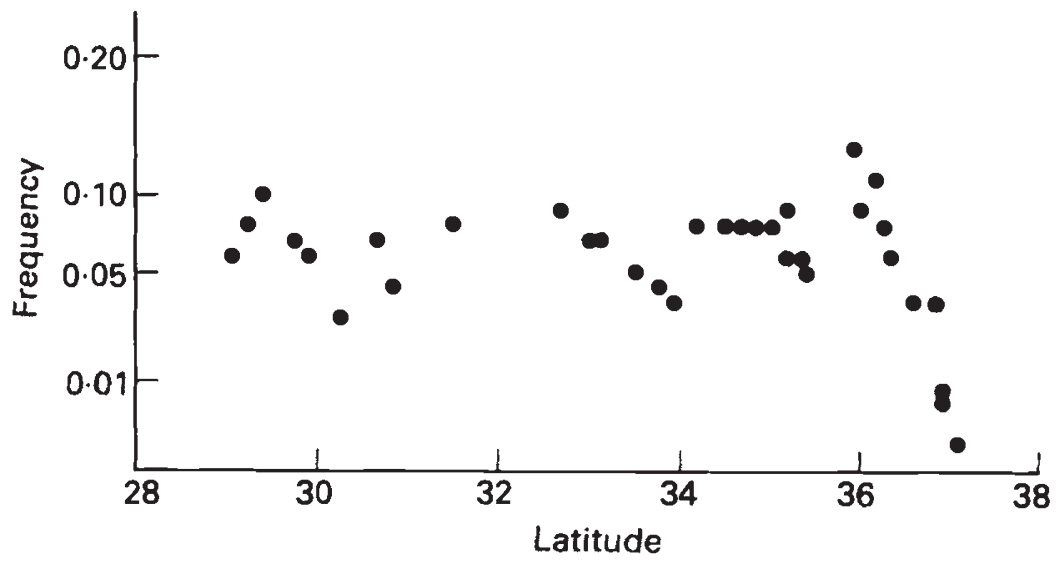

FIG. 3.-Relationship between the frequency of the incomplete-striped morph and latitude. Morph frequencies have been subjected to angular transformation. 


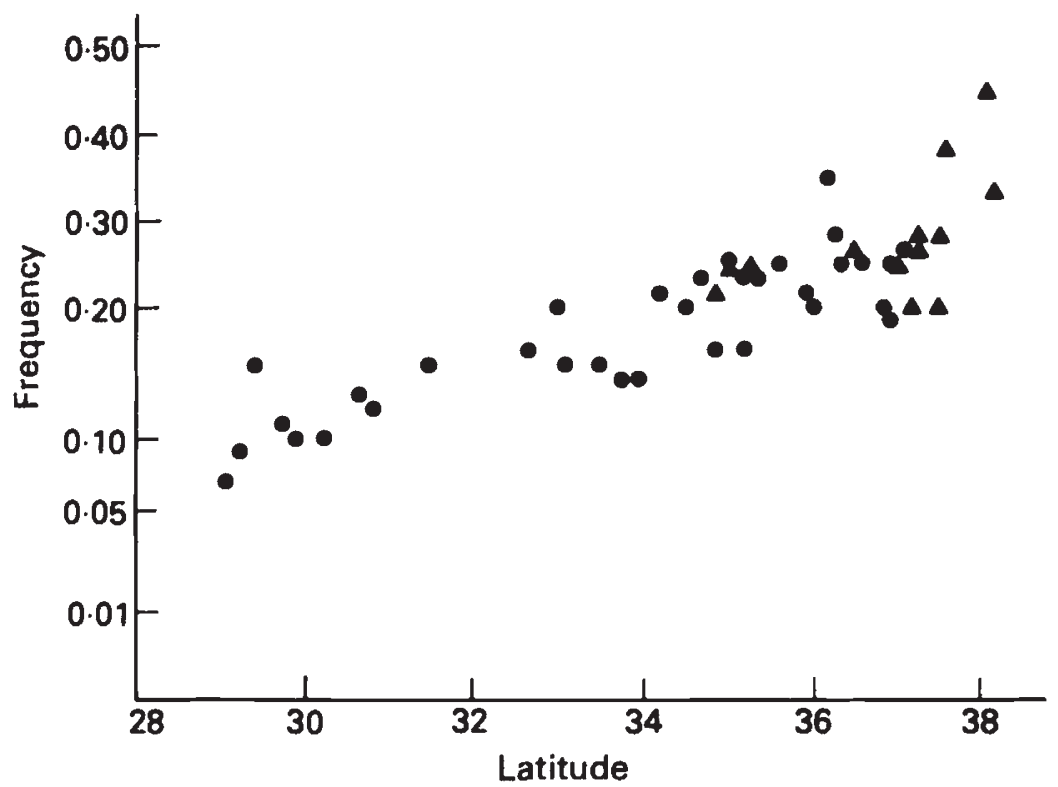

FIG. 4.-Relationship between the frequency of total striped morphs (incomplete-striped plus striped) and latitude for the 1979/80 transect collection sites $(O)$ and the 1978 collection sites $(\boldsymbol{A})$. Morph frequencies have been subjected to angular transformation. (Least squares linear regression line is $y$ (angles) $=1.44 x-22 \cdot 47, F=119 \cdot 77, P<0 \cdot 001$ ).

that have been carried out indicate that the genetic basis of the colour pattern variation is more complex. In the Australian plague locust, Chortoicetes terminifera, there are 9 colour pattern morphs determined by combinations of 4 allelic genes (Byrne, 1967) though later work on this system suggests that the alleles map to separate loci (Hawke, 1974). Fourteen genes affecting colour pattern were detected in the meadow grasshopper, Chorthippus parallelus (Sansome and La Cour, 1935) while in a grouse locust Paratettix texanus 23 colour pattern genes were found (Nabours, 1929). The pattern polymorphism in $P$. vittatum which can be scored in all life-history stages except the egg stage and which has a simple genetic basis would appear to offer an excellent opportunity to study the action of selection both in the field and the laboratory.

The results of the geographic survey show that there is a marked cline in the frequency of the alleles determining the colour pattern polymorphism. Three cautionary points need to be made in relation to these data. First, all collections have been made from grazed pastures where $P$. vittatum is extremely abundant and large collections are readily obtained. However, these habitats have resulted from the recent activities of European man and prior to $1800 \mathrm{P}$. vittatum would have been more limited to open woodland habitats. No collections have yet been made in woodland habitats where $P$. vittatum is found at low density but casual observations suggest that the frequency of striped individuals is low.

Second, the man-made disturbances to habitats in Australia, in particular the practice of large-scale forest clearing and the creation of grazing 
pastures, could mean we are observing a non-equilibrium situation in the case of the latitudinal cline. However, while the one generation a year life history pattern of $P$. vittatum would increase this possibility, the species is very abundant and is continuously distributed. Moreover, the macropterous morph of this species would ensure a high degree of gene flow.

Third, no account has been taken of temporal variation in the frequency of striped individuals. Preliminary unpublished observations of temporal variation at one site near Melbourne show small changes between different sample times over the summer. The cause of this variation is unknown but could be due to differential trapping between the two morphs under different climatic conditions. This variation does not, however, negate the existence of the latitudinal cline but would presumably add a degree of noise.

The latitudinal cline in gene frequency suggests the possibility of a corresponding cline in selection differentials between the genotypes segregating at the colour pattern locus. Clearly, a number of environmental variables affecting the survival and fecundity of grasshoppers will show variation over a $1140 \mathrm{~km}$ north/south transect and the most obvious variable is temperature since grasshoppers have high heat requirements and are extremely sensitive to small variations in temperature. However, while conditions generally get warmer towards the north, this relationship is complicated in the case of $P$. vittatum by the fact that this species in only found at increasing altitudes with decreasing latitude. An examination of data collected by meteorological stations along the transect shows that the temperature differential over the transect is not great. To complicate matters further it must be remembered that with decreasing latitude there is decreasing day length during the summer months which will restrict the total solar radiation received by the grasshoppers. Overall, therefore, it is difficult to define the transect in terms of a potentially relevant temperature variable. Nevertheless, the different colour patterns will inevitably lead to differences in internal body temperatures though whether these differences are great enough to exert selection differentials at the colour pattern locus remains to be determined.

Variable colouration in acridoid grasshoppers appears to be associated with a geophilous habit and grassland habitats, a reflection, it has been proposed, of seasonal changes and local variation in the prevailing colour of the background (Rowell, 1971). This argument presumes that the prime adaptive value of the colour pattern is through crypsis (Isely, 1938). If crypsis is important then the longitudinal striping pattern displayed by $P$. vittatum, termed disruptic colouration by Rowell (1971), would provide excellent camouflage against the usual habitat background colour, a mosaic of patches of dark soil and patches of dry grass. This argument does not in itself provide an explanation for the observed cline, however, since the background colour of the pasture sites where collections were made was similar over the whole cline. A possibility that is being examined is that it is the relationship between pasture and woodland sites that is responsible for the observed cline and that the polymorphism is maintained at particular localities by gene flow imposed on a regime of disruptive selection between pasture and woodland habitats. The proximity of adjacent woodland would appear to increase with decreasing latitude for these collection sites, especially as $P$. vittatum is restricted to progressively higher altitudes 
with decreasing latitude, and this could provide an explanation for the cline.

Finally, the determination of the genetic basis of the colour pattern polymorphism in $P$. vittatum makes the observation of partial non-assortative mating with respect to the colour pattern morphs in this species (Dearn, 1979) particularly interesting. The significance of the non-random mating pattern has yet to be determined but even though the effect is small it could clearly play a role in the maintenance of the polymorphism.

Acknowledgements.-I am most grateful to the Pastures Protection Board of N.S.W. for financial assistance for field work, to Wendy Phillips for her excellent assistance in the laboratory, and to John McKenzie for his constructive criticism of the manuscript.

\section{REFERENCES}

BYRNE, O. R. 1967. Polymorphism in the Australian Acrididae I. Inheritance of colour patterns in the plague locust, Chortoicetes terminifera. Heredity, 22, 561-568.

CLARK, D. P. 1962. An analysis of dispersal and movement in Phaulacridium vittatum (Sjöst.) (Acrididae), Aust. J. Zool., 10, 383-399.

CREIGHTON, M., AND ROBERTSON, W. R. B. 1941. Genetic studies on Chorthippus longicornis. J. Heredity, 32, 339-341.

DEARN, J. M. 1978. Polymorphisms for wing length and colour pattern in the grasshopper Phaulacridium vittatum (Sjöst). J. Aust. ent. Soc., 17, 135-137.

DEARN, J. M. 1979. Evidence of non-random mating for the colour pattern polymorphism in field populations of the grasshopper Phaulacridium vittatum. J. Aust. ent. Soc., 18, 241-243.

GILL, P. D. 1979. Colour-pattern variation in relation to habitat in the grasshopper Chorthippus brunneus (Thunberg), Ecological Entomology, 4, 249-257.

HAWKE, A. D. 1974. Genetic studies of polymorphism in laboratory and natural populations of the Australian plague locust, Chortoicetes terminifera. Ph.D. Thesis, Australian National University.

ISELY, F. B. 1938. Survival value of acridien protective coloration. Ecology, 19, 370-389. KEY, K. H. L. 1938. The regional and seasonal incidence of grasshopper plagues in Australia. Bull. Counc, scient. ind, Res., Melb., 117.

KING, R. L., AND SLIFER, E. H. 1955. The inheritance of red and blue hind tibiae in the lesser migratory grasshopper. J. Hered., 46, 302-304.

NABOURS, R. K. 1929. The genetics of the Tettrigidae (grouse locusts). Bibliographia Genetica, 5, 27-104.

PETERSEN, B., AND TREHERNE, J. E. 1949. On the distribution of colour forms in Scandinavian Omocestus viridulus L. Oikos, 1, 175-183.

ROWELL, C. H. 1971. The variable coloration of the Acridoid grasshoppers. Advanc. Insect Physiol., 8, 145-198.

SANSOME, F. W., AND LA COUR, L. 1935. The genetics of grasshoppers: Chorthippus parallelus. Journal of Genetics, 30, 415-422.

UVAROV, B. P. 1966. Grasshoppers and Locusts. A handbook of General Acridology. Volume 1. Cambridge University Press. 